\title{
BOOKS REVIEW
}

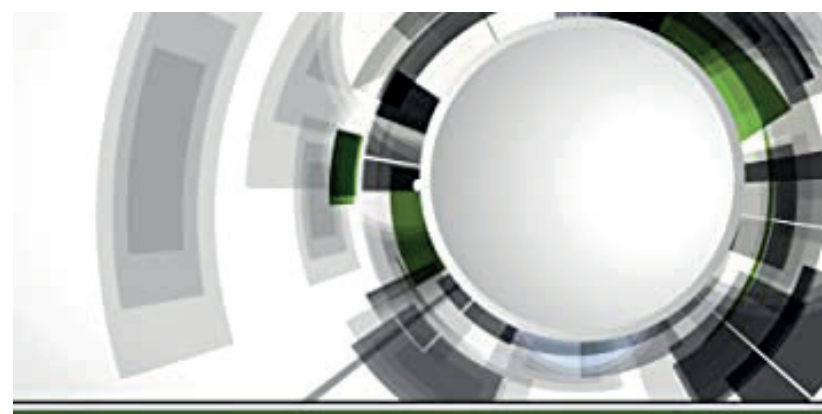

Buying and Selling the Environment

How to Design and implement a PES Scheme

GABRIELA SCHEUFELE JEFF BENNETT

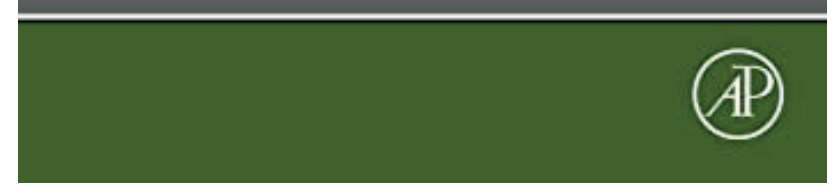

\section{BUYING AND SELLING THE ENVIRONMENT - HOW TO DESIGN AND IMPLEMENT A PES SCHEME}

\section{Edited by Gabriela Scheufele and Jeff Bennett}

Payments for environmental services (PES) are attracting growing interest worldwide as the natural capital becomes increasingly depleted under mounting, often conflicting, land-use pressures, proving definitely greater than socially optimal due to different sources of market failure (e.g., presence of externalities, public recognition of the majority of natural assets, imperfect definition of property rights and asymmetry of information).

PES are widely recognized as cost-effective policy instruments of use in improving environmental protection and management, and rewarding people for their efforts in providing environmental and ecosystem services, such as biodiversity conservation, soil stabilization, carbon storage and sequestration, etc.

PES are voluntary transactions between the consumer and the provider, conditional to the provider securing service provision (Wunder, 2005). They explicitly recognize the need to match the interests of landowners and users both to societal and external interests and internalize what would otherwise be an externality (Engel et al., 2008). The conversion of natural ecosystem areas for anthropogenic activities has progressively reduced the wilderness and natural habitats, thus constituting an increasing threat to environmental services. This ever-emerging scarcity renders environmental services potentially subject to trade, as external beneficiaries of environmental services might be willing to pay landowners to implement the best practises to ensure environmental and ecosystem conservation and restoration. In this respect, PES schemes can be viewed as an attempt to implement the Coase Theorem (Coase, 1960), or alternatively as a subsidy to environmental service providers, eventually combined with a user fee for consumers of environmental services. In this context, PES schemes are an alternative to the direct governmental provision of environmental services and a means of correcting market failures or policy distortions. Nonetheless, PES are unable to address any environmental issues and their scope for application is limited to problems in which externalities play a major role and voluntary approaches are unlikely to be effective and efficient. The successful implementation of PES schemes is indeed affected by the nature of environmental services as public or club goods. PES programs differ in design characteristics and reflect the social, economic and political context in which they are implemented.

Buying and Selling the Environment - How to Design and Implement a PES Scheme, edited by Gabriela Scheufele and Jeff Bennett and recently published by Elsevier, provides an overview on the creation of operational and efficient PES schemes. The stimulus for the book derives from a research project commissioned by the Australian Center for International Agricultural Research (ACIAR) to explore the feasibility of adopting PES schemes for the management of natural resources in the Lao People's Democratic Republic (Lao PES scheme). The book consists of nine chapters and seven annexes, presents a step-by-step approach to the design of PES schemes with a core focussed on applied economics. Chapter 1 provides a general introduction and a road map to readers, as well as the economic foundations and basic principles underpinning PES and PES schemes. In Chapter 2, the characteristics of PES scheme contexts are described, the rationale for developing and implementing a PES scheme is discussed and alternative schemes are investigated. Chapter 3 analyzes the biological and physical background of any PES scheme and the relationship between environmental management actions and their potential outcomes, with the aim of identifying actions to be performed by sellers and benefits gained by buyers. Chapter 4 investigates market 
demand and buyers' willingness to pay for environmental services and describes the most widely implemented techniques to elicit individual preferences and individuals' willingness to pay, whereas Chapter 5 is centred on market supply and sellers' willingness to accept payments to provide environmental services. Chapter 6 describes the PES markets and the equilibrium price is identified, whilst Chapter 7 analyses contractual agreements and the role of intermediaries and brokers. In Chapter 8, performances of PES scheme are assessed and discussed and potential improvements focussed on increasing the cost-effectiveness of PES schemes are investigated. Finally, Chapter 9 provides a review of the main concepts presented in previous chapters, analyzes advantages and pitfalls and presents an overview of the contexts in which PES schemes are most likely to be successfully implemented. In each Chapter, a reference to the application of concepts discussed in the specific context of the Lao People's Democratic Republic is made, and materials produced in the Lao PES scheme project are provided in annexes.

The book is mainly intended as an instruction manual for practitioners, policy makers and advisors in governmental and non-governmental organizations, providing an insight into practical issues and barriers to the design and implementation of efficient PES schemes in real world situations. The volume provides a user-friendly step-by-step guidance of PES schemes, reviews the underpinning basic economic principles and enhances practical knowledge through a case study of natural resource management.

Chiara D'Alpaos

University of Padova, Italy

e-mail: chiara.dalpaos@unipd.it

\section{REFERENCE}

Coase, R.H., 1960. The problem of social cost. Journal of Law and Economics 3, pp. 1-44.

Wunder, S., 2005. Payments for Environmental Services: Some Nuts and Bolts. Occasional Paper No. 42. CIFOR, Bogor.

Engel, S., Pagiola, S., Wunder, S., 2008. Designing payments for environmental services in theory and practice: An overview of the issues. Ecological Economics 65(4), pp. 663-674.

\section{ABOUT THE EDITORS}

\section{Gabriela Scheufele}

Gabriela Scheufele is a Visiting Research Fellow in the Crawford School of Public Policy at the Australian National University. Her current research is focused on designing and implementing a payments for environmental services (PES) scheme in Lao PDR. Her research interests include non-market valuation, conservation auctions, market-based instruments in environmental and natural resource management, and incorporating environmental and natural resource economics research into policy development.

\section{Jeff Bennett}

Jeff Bennett is Professor in the Crawford School of Public Policy at the Australian National University. He is an international recognised environmental and resource economist who specialises in the analysis of the private sector in protecting the environment and the estimation of non-market benefits and costs.

\section{Book Info:}

Editors: Gabriela Scheufele, Jeff Bennet

Imprint: Elsevier

Year of publication: 2019

Page Count: 218

Paperback ISBN: 9780128166963 